\title{
CHANGES IN THE SURFACE PROPERTIES OF INORGANIC- ORGANIC FILMS CAUSED BY WATER ATTACK
}

\author{
JANA PAGÁČOVÁ*, IVETA PAPUČOVÁ*,, ALFONZ PLŠKO**, KATARÍNA FATURÍKOVÁ** \\ *Alexander Dubček University of Trenčin, Faculty of Industrial Technologies, \\ I. Krasku 491/30, 02001 Púchov, Slovak Republic \\ **FunGlass - Centre for Functional and Surface Functionalized Glass, Alexander Dubček University of Trenčin, \\ Študentská 2, 91150 Trenčin, Slovak Republic \\ "E-mail: iveta.papucova@tnuni.sk
}

Submitted October 19, 2021; accepted January 21, 2022

\begin{abstract}
Keywords: Sol-gel, Inorganic-organic films, Water attack, Surface morphology, Hydrophobicity
The paper deals with studying the changes in the surface properties of inorganic-organic films after their interaction with water. The inorganic-organic films were deposited from sols, which were prepared at room temperature as well as the boiling temperature of isopropyl alcohol by three different ways of mixing the initial precursors - tetraethoxysilane (TEOS), triethoxy(octyl)silane (OTES), isopropyl alcohol, distilled water and nitric acid. The films, which were prepared by the dipcoating technique and treated at $170{ }^{\circ} \mathrm{C}$, were exposed to a water attack at $80^{\circ} \mathrm{C}$ for 5 hours. To characterise the films, after their interaction with water, changes in the morphology, rms-roughness and hydrophobicity were used. The studied properties were investigated, using the atomic force microscopy and sessile drop technique. All the films were hydrophobic, and their hydrophobicity was without any change or it was only slightly increased after the water attack. On the basis of the results, it can be stated that the way that the sol is prepared as well as the water attack have the smallest effect on the changes in the surface morphology of a film deposited from a sol where OTES was added to TEOS at the beginning of the sol preparation and they were hydrolysed simultaneously at room temperature. The rms-roughness and water contact angle for this film were only slightly increased after the water attack.
\end{abstract}

\section{INTRODUCTION}

A material's surface is crucial for its interaction with the surrounding environment. Its nature markedly affects and delimits the final mechanical, chemical and optical properties of the material. In the application of materials and in the determination of their properties, their surface chemistry plays a crucial role, as the surface is affected by interactions not only inside the material, but also at its interface with the surrounding environment. That is why materials are very often surface treated $[1,2]$.

The application of functional films is one way to improve the surface properties [3-5]. To prepare films, the sol-gel method is an advantageous selection, either using the spinning, spraying or dipping method [6-8].

Silica-based functional films can be deposited on various materials including glass [9, 10], steel, aluminium, copper [11, 12], silicon substrates [13], magnesium alloys [5, 14] in the function of anticorrosion films to increase the corrosion resistance of a material or in the function of hydrophobic, selfcleaning and antibacterial films.

In [11], films were applied on aluminium substrates by the sol-gel method, using 3-glycidoxypropyltrimethoxysilane as the main precursor and N,N-dimethylthiourea was added in order to improve the corrosion resistance. The inhibition effect of the films was investigated by electrochemical impedance and polarisation, and a significant improvement in the corrosion resistance of the substrate was confirmed. Anticorrosion and hydrophobic films on copper substrates were also obtained from sols with methyltriethoxysilane [12]. Functional films prepared by the sol-gel method using tetraethoxysilane (TEOS) as a precursor were applied to historical glass in order to increase its resistance to pollutants in the atmosphere [15]. Moreover, besides applications to glass to improve the glass corrosion resistance to water $[9,16]$, functional films were used as coatings for the protection of cultural heritage glass $[17,18]$. 
Inorganic-organic hybrid films are an interesting group of functional films. In hybrid films, inorganic components increase the hardness, abrasion resistance, stiffness, and refractive index of thin films, and organic components increase the adhesion of thin films on a substrate as well as the wettability of a thin film surface (hydrophobicity) [19]. In comparison with the films mentioned above, inorganic-organic films are prepared at lower temperatures. These films have many advantages because they combine the properties of inorganic and organic components and, therefore, they can be water, chemical, abrasion, and UV resistant as well as hydrophobic [20-22].

Silica-based inorganic-organic protection films can be deposited on different materials, such as metal substrates [3, 4, 14, 23-26], polycarbonate substrates [27] and glass [28-31] having the function of anticorrosion, anti-fogging, superhydrophobic, selfcleaning, water-repellent, antistatic, scratch resistant and as antimicrobial coatings [32]. However, there are only a few studies dealing with inorganic-organic films deposited on glass from the aspect of the interaction between the surface of the films and the surrounding environment [33-35].

The dip-coating technique was used to apply sols to a steel surface, where the sols were prepared from tetraethoxysilane (as the $\mathrm{SiO}_{2}$ source), 3-(trimethoxysilyl) propylmethacrylate and methylmethacrylate (as the polymeric components) and $\mathrm{HCl}$ (as an acidic catalyst). An analysis of the corrosion resistance of the coated substrates was carried out by the electrochemical polarisation technique, using a computerised potentiostat while electron microscopy was used to observe the surface homogeneity. The films applied to the metal increased the corrosion resistance in $\mathrm{HCl}$ [3].

In the work [33], inorganic-organic films were used as protective coatings on glass materials. TEOS, as the silica precursor, was separately functionalised with different organo-functional precursors: octyltriethoxy-silane, hexadecyltrimethoxysilane, [3-(methacryloyloxypropyltrimethoxysilane,3glycidyloxy-propyl-methyldiethoxysilane and gammaaminopropyltriethoxy-silane. The films were applied to glass microscope slides by the dip-coating technique, where they were then exposed to model ageing tests, and the static contact angles were measured. The best results of the resistance to weathering effects were achieved when films from TEOS, which were functionalised with long alkyl chains, were used.

In the work [34], inorganic-organic films, prepared by the dip-coating technique, were used for the protection of historical window glass. The sols were prepared from TEOS, as the main precursor, with different ratios of Si-alkoxides functionalised with different alkyl groups: triethoxy(octyl)silane (OTES), hexadecyltrimethoxysilane(HDTMS),3-(trimethoxysilyl)-propylmethacrylate, trimethylethoxysilane and methyltriethoxysilane.
The chemical resistance was studied, when exposing the films to UV light and the atmosphere with different amounts of $\mathrm{SO}_{2}$, and the contact angles were observed and colorimetric measurements were taken. The films prepared from sols with the long alkyl chains (HDTMS and OTES) were stable from the aspect of the UV ageing as well as the corrosion tests.

The aim of this work is to study the changes in the surface properties of inorganic-organic films after their interaction with water. The films were deposited from sols in a "tetraethoxysilane - triethoxy(octyl)silane - water - nitric acid - isopropyl alcohol" system, while the given sols were prepared under different conditions. The changes in the film's surface were evaluated on the basis of the morphology, rms-roughness and hydrophobicity. These properties are used for the characterisation of the surface state and are some of the various indicators used to evaluate protective films.

\section{EXPERIMENTAL}

\section{Materials}

The inorganic-organic sols were prepared in a "TEOS-OTES-H2O-HNO3-IPA" system from tetraethoxysilane (TEOS; $98 \%$; Acros Organics), triethoxy(octyl)silane (OTES; $97 \%$; Acros Organics), distilled water $\left(\mathrm{H}_{2} \mathrm{O}\right.$; TnUAD), nitric acid $\left(\mathrm{HNO}_{3} ; 65 \%\right.$; Centralchem) and isopropyl alcohol (IPA; $99.7 \%$; Centralchem).

\section{Preparation of sols}

The molar composition of six inorganic-organic sols was: $x$ (TEOS) : $x$ (OTES) $: x\left(\mathrm{H}_{2} \mathrm{O}\right): x\left(\mathrm{HNO}_{3}\right): x($ IPA $)$ $=0.035: 0.015: 0.300: 0.005: 0.645$, respectively, while the following molar ratios were used: $x\left(\mathrm{H}_{2} \mathrm{O}\right)$ $:(x$ (TEOS $)+x($ OTES $))=6$ and $x$ (OTES $):(x$ (TEOS $)+$ $x(\mathrm{OTES}))=0.3$.

The sols were prepared at room temperature or at the boiling temperature of IPA according to three different procedures. The first sol, designated as BA, was prepared by mixing a solution containing IPA and TEOS (40\% of IPA $+100 \%$ of TEOS) with a solution containing IPA, $\mathrm{H}_{2} \mathrm{O}$ and $\mathrm{HNO}_{3}\left(40 \%\right.$ of IPA $+100 \%$ of $\mathrm{H}_{2} \mathrm{O}+$ $100 \%$ of $\mathrm{HNO}_{3}$ ), and finally, after 1 hour of mixing, a solution containing IPA and OTES (20\% of IPA $+100 \%$ of OTES) was added. The final BA sol was also mixed for 1 hour. The second sol, designated as BB, was prepared by mixing a solution containing IPA, TEOS, and OTES $(50 \%$ of IPA $+100 \%$ of TEOS $+100 \%$ of OTES $)$ with a solution containing IPA, $\mathrm{H}_{2} \mathrm{O}$ and $\mathrm{HNO}_{3}(50 \%$ of IPA $+100 \%$ of $\mathrm{H}_{2} \mathrm{O}+100 \%$ of $\mathrm{HNO}_{3}$ ) and the final $\mathrm{BB}$ sol was mixed for 2 hours. The third sol, designated as BC, was prepared from two individual solutions which were mixed together for 1 hour. The content of one solution 
was based on IPA, TEOS, $\mathrm{H}_{2} \mathrm{O}$ and $\mathrm{HNO}_{3}$ (70 \% of IPA $+100 \%$ of TEOS $+70 \%$ of $\mathrm{H}_{2} \mathrm{O}+70 \%$ of $\mathrm{HNO}_{3}$ ), and the other solution was comprised of IPA, OTES, $\mathrm{H}_{2} \mathrm{O}$ and $\mathrm{HNO}_{3}(30 \%$ of IPA $+100 \%$ of OTES $+30 \%$ of $\mathrm{H}_{2} \mathrm{O}+30 \%$ of $\mathrm{HNO}_{3}$ ). The introduced individual solutions were mixed for 1 hour. The BA, BB and $\mathrm{BC}$ sols were prepared at room temperature. The sols, designated as $\mathrm{BD}, \mathrm{BE}$ and $\mathrm{BF}$, were prepared in the same way of mixing as the $\mathrm{BA}-\mathrm{BC}$ sols, however, at a higher temperature (the boiling temperature of IPA) and with longer mixing time intervals. During the preparation, the individual solutions as well as the final $\mathrm{BD}, \mathrm{BE}$ and $\mathrm{BF}$ sols were mixed for 3, 6 and 3 hours, respectively.

\section{Preparation of films}

One day after preparing the individual sols, the dipcoating technique (withdrawal speed of $40 \mathrm{~mm} \cdot \mathrm{min}^{-1}$ ) was used to prepare the film on glass substrates (glass microscope slides, which were cleaned with detergent, water, distilled water and IPA, and then dried). After deposition of the individual sols, the films were treated for 2 hours at a temperature of $170^{\circ} \mathrm{C}$, and then they were left to cool to room temperature. All the prepared films were transparent and colourless, and their geometrical thickness was about $200 \mathrm{~nm}$.

\section{Interaction of films with water}

The individual films were vertically inserted into polypropylene bottles with $100 \mathrm{ml}$ distilled water. The films were in contact with the water for 5 hours at a temperature of $80^{\circ} \mathrm{C}$. After that, the films were rinsed with distilled water and IPA, and they were dried for 30 minutes at a temperature of $80{ }^{\circ} \mathrm{C}$. The films were designated as BAk-BFk after the water attack.

\section{Characterisation of films}

Before and after their interaction with water, the films' surface was characterised by atomic force microscopy (AFM) and the hydrophobicity was also determined.

The measurements of the films' surface were carried out by a Bruker Innova ${ }^{\circledR}$ atomic force microscope in a tapping mode at a frequency of $300 \mathrm{kHz}$ (RTESPA-300 tip) at room temperature and the relative humidity. The surface of each film was measured at randomly chosen places. NanoScope 1.5 Analysis software was used to process the surface morphology and topography.

The contact angles of the distilled water were determined by the sessile drop technique [36], using at least 10 droplets of a $10 \mu \mathrm{l}$ volume for each film. The contact angles of the water were calculated from the droplet profiles by the non-linear least squares method in Matlab software.

\section{RESULTS AND DISCUSSIONS}

\author{
Morphology of films
}

Figures 1 and 2 show the AFM images of the surface of the films, which were deposited from the sols prepared at room temperature as well as the boiling temperature of IPA, respectively. The films in the mentioned figures represent the films' surface before (a-c) and after (d-f) their interaction with the water. From the given figures, it can be seen that the surface morphology of the inorganic-organic films is affected not only by how the initial precursors were mixed and by the temperature during the sol preparation, but also by the interaction with the water. The interaction of the $\mathrm{BA}, \mathrm{BD}, \mathrm{BC}$ and $\mathrm{BF}$ films with the water markedly and mainly affected the surface morphology of these films. The given films were deposited from sols, which were prepared by adding OTES to the mixture, where only TEOS was pre-hydrolysed (BA and BD sols/films), and from sols, where TEOS and OTES were hydrolysed separately before they were mixed (BC and BF sols/ films).

After the water interaction with the BA film, which was deposited from a sol prepared at room temperature, the removal of the non-uniformly distributed cavities from the film surface was observed (Figure 1a). The mentioned cavities had circular (diameters in the range of $0.5-2.3$ $\mu \mathrm{m})$ and irregular shapes (dimensions in the range of $3.5-10 \mu \mathrm{m})$. After the water attack, a film surface with fine granular shapes and almost uniformly distributed cavities of predominantly circular shape were obtained (BAk film, Figure 1d). The given circular cavities had diameters in the range of $0.2-1.0 \mu \mathrm{m}$, while the same number of individual cavities of similar dimensions was observed. The depth of the cavities increased from the range of $30-100 \mathrm{~nm}$ to the range of $90-180 \mathrm{~nm}$ after the water attack. The water action caused the removal of the film surface which was created by larger circular and irregular cavities. Moreover, new smaller circular cavities were created, and, probably, there was also an increase in the depth of the existing cavities with smaller diameters.

The water interaction with the BB film did not significantly change the morphology of its surface (Figure 1b). The surface of the BBk film was also uniform referring to the distribution of small granular shapes and cavities (Figure 1e). There was only a small change in the dimensions of some irregular cavities from the range of $0.2-0.7$ $\mu \mathrm{m}$ to $0.2-1.2 \mu \mathrm{m}$ before and after the water attack, respectively. The depth of the cavities correlated with their dimensions, which slightly increased from a range of $10-40 \mathrm{~nm}$ to $10-60 \mathrm{~nm}$ after the water attack.

The surface of the BC film (Figure 1c), which was created from irregular ridged shapes (their width and height were in the range of $3-10 \mu \mathrm{m}$ and $50-160 \mathrm{~nm}$, respectively), was markedly changed after its interaction with water. After the water attack, these ridged shapes 
were removed from the surface, and there was a nonuniform rugged surface formed from little granular shapes and cavities as well as large shallow circular and irregular cavities (Figure 1f). The large circular cavities had a "diameter" from $2 \mu \mathrm{m}$ and some irregular large cavities had a dimension even bigger than $9.5 \mu \mathrm{m}$. The large cavities had a depth in the range of $10-60 \mathrm{~nm}$.
(Figure 2d). It seems that the large cavities were created by the connection of circular cavities at several places and their "diameter" was in the range of $1.6-3 \mu \mathrm{m}$.

The surface of the BE film consisted of non-uniformly distributed granular shapes and their aggregates (Figure $2 \mathrm{~b}$ and its cut). After the water interacted with the film, the mentioned granular shapes were removed from

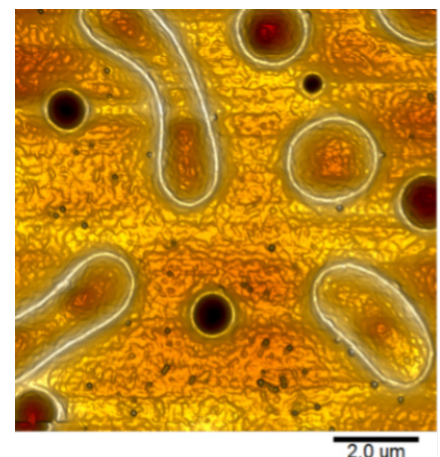

a)

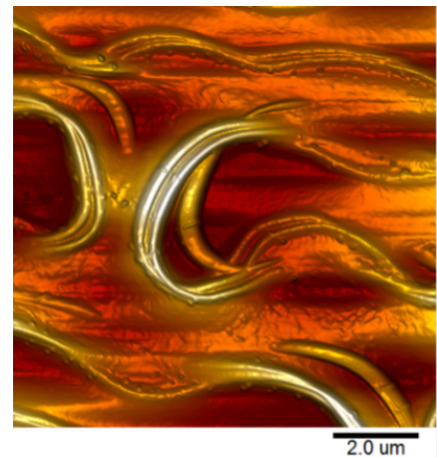

c)

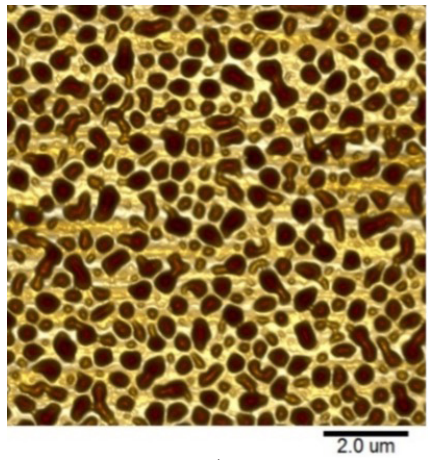

e)

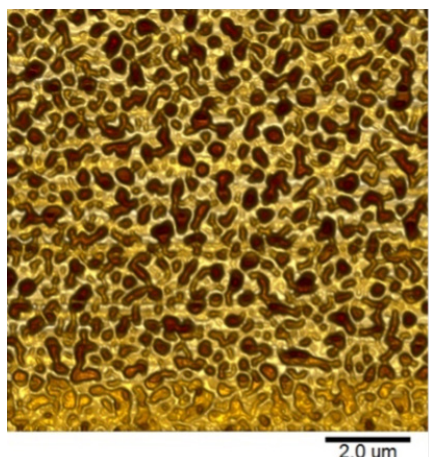

b)

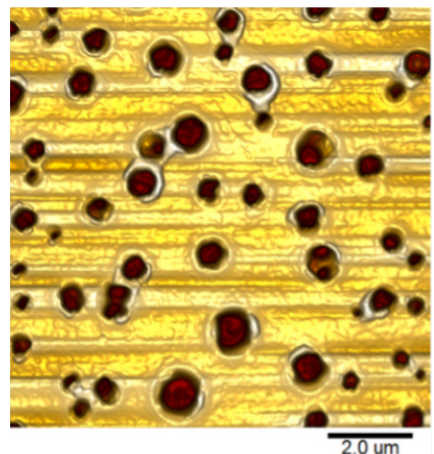

d)

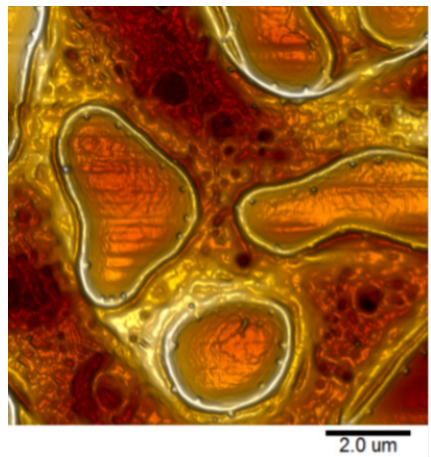

f)

Figure 1. The AFM images of the film surface before: a) BA, b) BB, c) BC, and after the water attack: d) BAk, e) BBk, f) BBk; the sols for the given films were prepared at room temperature.

The surface of the BDk film, deposited from the sol prepared at the boiling temperature of IPA, was considerably different from the surface of the BD film. The BD film was rugged, with non-uniformly distributed larger irregular granular shapes and cavities (Figure 2a). After the water attack, there was a significant violation of the BDk film surface and mutually connected large cavities with a depth from 100 to $200 \mathrm{~nm}$ were created the film surface and a non-uniform rugged surface of the BEk film with small granular shapes and cavities was observed (Figure 2e and its cut). After the water attack, the dimensions of the cavities on the surface of the BEk film were slightly larger, and similar findings were observed for the $\mathrm{BB}$ and $\mathrm{BBk}$ films deposited from the sol which was prepared in the same way of mixing the initial precursors as was in the case of the sol 
for the BE and BEk films, but it was at room temperature. A significant change in the film surface was also observed for the BF film after it interacted with the water. After the water attack, cupola shapes (with a height up to $160 \mathrm{~nm}$ ) on the surface of the BF film (Figure 2c) were changed to little ridged shapes with a height up to $\sim 10 \mathrm{~nm}$ or even to irregular large cavities with a depth in a range of $10-150 \mathrm{~nm}$ (Figure 2f). The dimensions of these ridged shapes and large cavities were in the range of $1.4-5.5 \mu \mathrm{m}$ and up to $\sim 8 \mu \mathrm{m}$, respectively. is prepared at room temperature and the boiling temperature of IPA, respectively.

In the case of the films deposited from sols prepared at room temperature, the water action had an effect on the $r m s$-roughness of the BA and BB films, i.e., films prepared from the sol where OTES was added to the pre-hydrolysed TEOS (BA sol), and from the sol where TEOS and OTES were hydrolysed simultaneously (BB sol). The water attack caused a significant increase

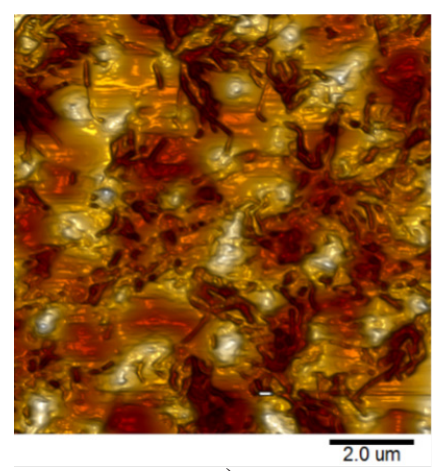

a)

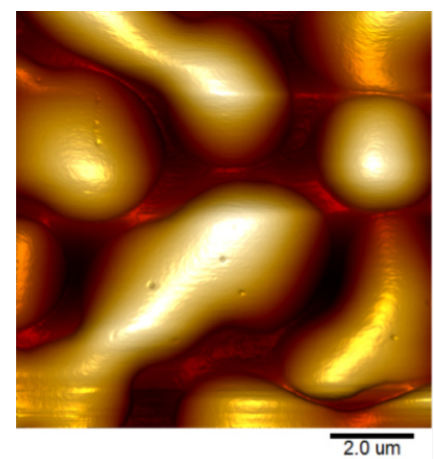

c)

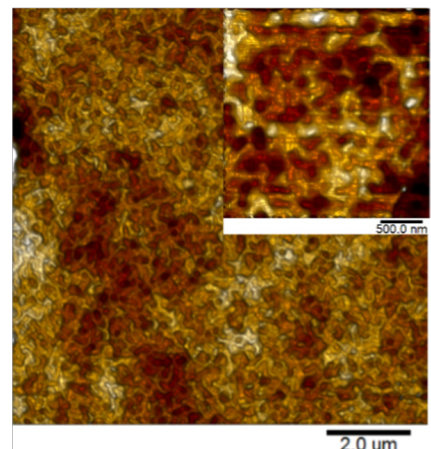

e)

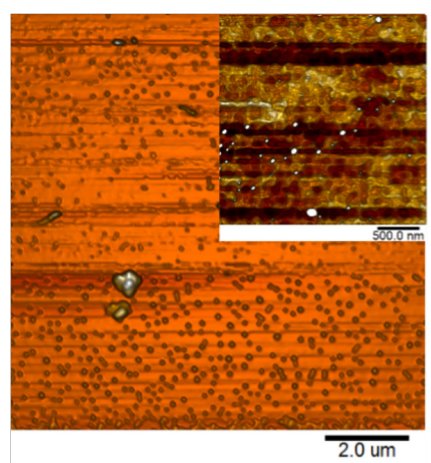

b)

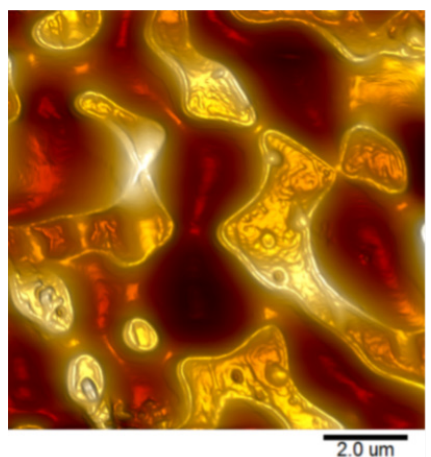

d)

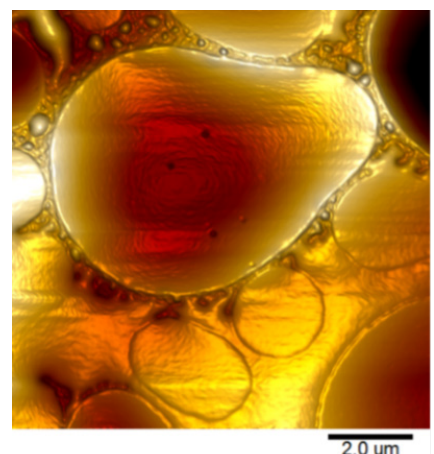

f)

Figure. The AFM images of the film surface before: a) BD, b) BE, c) BF, and after the water attack: d) BDk, e) BEk, f) BFk; the sols for the given films were prepared at the boiling temperature of IPA.

\section{$R m s$-roughness of films}

Figures 3 and 4 show the dependence of the $r m s$-roughness of the films before and after the water interaction with their surface on the way of the sol in the rms-roughness average value from $\sim 10 \mathrm{~nm}$ (for the BA film) to $\sim 37 \mathrm{~nm}$ (for the BAk film). This significant change in the rms-roughness is connected with the significant change in the surface morphology in consequence of the removal of certain places from 
the surface of the mentioned film after the water attack. For the BB film, the rms-roughness was slightly increased from the value of $\sim 8 \mathrm{~nm}$ to $\sim 14 \mathrm{~nm}$ for the BBk film because, after the water attack, the change in its surface morphology was not noticeable. The rms-roughness of the water-attacked $\mathrm{BCk}$ film remained the same as the $r m s$-roughness for the $\mathrm{BC}$ film before the water attack, although there was a noticeable change in the surface morphology of the water-attacked film, which was deposited from the sol where TEOS and OTES were pre-hydrolysed separately. It is probably the result of the large removal of shapes, after they created the film, as well as the increase in the depth at places between these shapes.

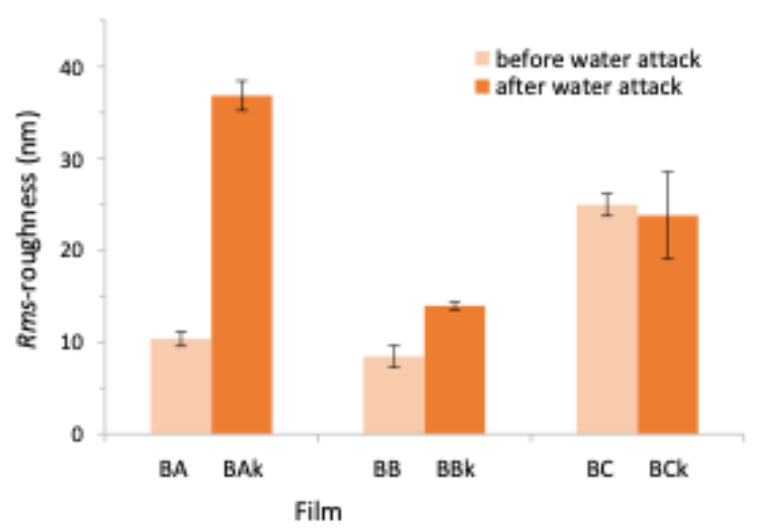

Figure 3. The influence of the way the sol was prepared at room temperature as well as the water attack on the surface rms-roughness of inorganic-organic films.

In the case of the films deposited from the sols prepared at the boiling temperature of IPA, the water attack caused a significant increase in the average value of the rms-roughness only for the film created from the sol where OTES was added to the pre-hydrolysed TEOS the $r m s$-roughness increased from $\sim 9 \mathrm{~nm}$ for the BD film to $\sim 49 \mathrm{~nm}$ for the BDk film. In the case of the other two ways the sol was prepared, the water interaction with the films caused a reduction in their $r m s$-roughness (from $\sim 7 \mathrm{~nm}$ for the BE film to $\sim 0.7 \mathrm{~nm}$ for the BEk film, and from $\sim 37 \mathrm{~nm}$ for the BF film to $\sim 20 \mathrm{~nm}$ for the BFk film). The reason for the increase or reduction in the average $r m s$-roughness of the $\mathrm{BDk}, \mathrm{BEk}$ and $\mathrm{BFk}$ films can be clearly seen in the changes in the surface morphology of these films in consequence of their water interaction. The water action caused the violation of the BD film surface and the significant removal of its parts, and the surface of the attacked film was "irregular" and its $r m s$-roughness was increased. The granular shapes on the surface of the BE film, which increased the rms-roughness of the film, were removed from the film surface during the water interaction of the given film. The $r m s$-roughness of the BF film was also reduced, because the water attack caused a change in the film surface by the removal of or reduction in the large cupola shapes on the film surface.

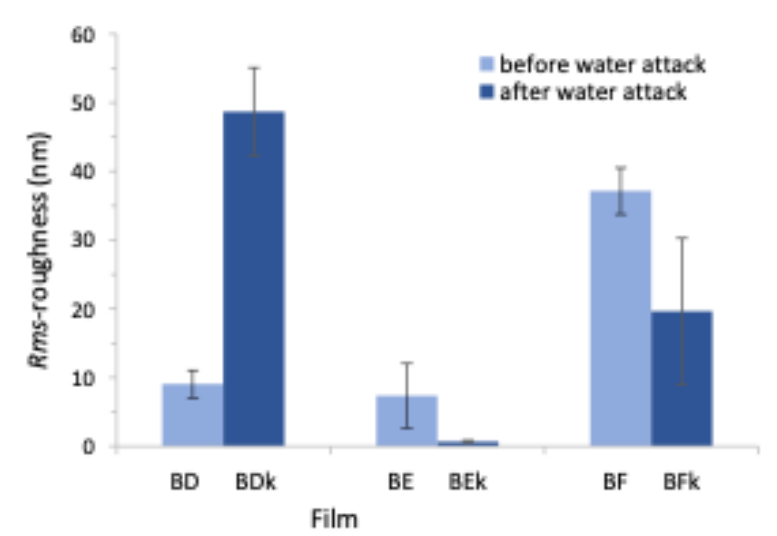

Figure 4 The influence of the way the sol was prepared at the boiling temperature of IPA as well as the water attack on the surface rms-roughness of inorganic-organic films.

In the case of the films before their water interaction, the way of mixing the initial precursors had an effect on the rms-roughness only for the films which were prepared from the sols where TEOS and OTES were pre-hydrolysed separately before they were mixed. The $\mathrm{BC}$ and $\mathrm{BF}$ films had the highest $r m s$-roughness in comparison with the other films for both sol preparation temperatures. After the water interaction with the films, the initial precursors mixing effect on the $r m s$-roughness was changed. After the water attack, the BAk and BDk films, which were deposited from sols where only TEOS was pre-hydrolysed, had the highest rms-roughness, and the BBk and BEk films, which were deposited from the sols where TEOS and OTES were hydrolysed simultaneously, had the lowest $r m s$-roughness.

\section{Hydrophobicity of films}

Figures 5 and 6 show the dependence of the contact angle of the films before and after the water interaction with their surface on the way the sols were prepared at room temperature and at the boiling temperature of IPA, respectively. All the films deposited from the sols prepared at the different conditions are hydrophobic before as well as after their water interaction.

For films deposited from sols prepared at room temperature (Figure 5), a slight increase in the average value of the contact angle of the water was observed after the water attack of the BA and BB films which were deposited from the sol where OTES was added to the pre-hydrolysed TEOS as well as from the sol where TEOS and OTES were hydrolysed simultaneously (from $\sim 97^{\circ}$ for the BA film to $\sim 100^{\circ}$ for the BAk film, and from $\sim 99^{\circ}$ for the BB film to $\sim 102^{\circ}$ for the BBk film). The mentioned increase in the contact angle can be explained by the changes in the distribution of the 
polar $(\mathrm{Si}-\mathrm{OH})$ and nonpolar groups ( $\mathrm{Si}-\mathrm{R}$ groups from OTES) on the surface of the film after its water interaction. During the water attack, the water primarily interacts with the polar $\mathrm{Si}-\mathrm{OH}$ groups and due to the leaching process, there are larger depths of "hydrophilic" places on the film surface (the creation of cavities with different dimensions, mainly on the surface of the BAk film). Subsequently, the places with nonpolar groups remain on the film surface and they contribute to an increase in the hydrophobicity.

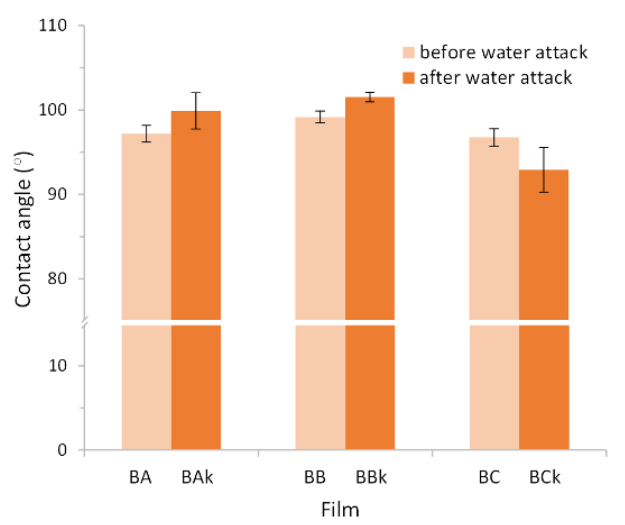

Figure 5. The influence of the way the sol was prepared at room temperature as well as the water attack on the water contact angle of the inorganic-organic films.

For the film deposited from the sol, where TEOS and OTES were pre-hydrolysed separately before they were mixed, the water attack caused a slight decrease in the water contact angle (from $\sim 97^{\circ}$ for the $\mathrm{BC}$ film to $\sim 93^{\circ}$ for the $\mathrm{BCk}$ film); the mentioned decrease is probably the result of a significant change in the film surface after its water interaction due to the removal of parts with a predominantly nonpolar character.

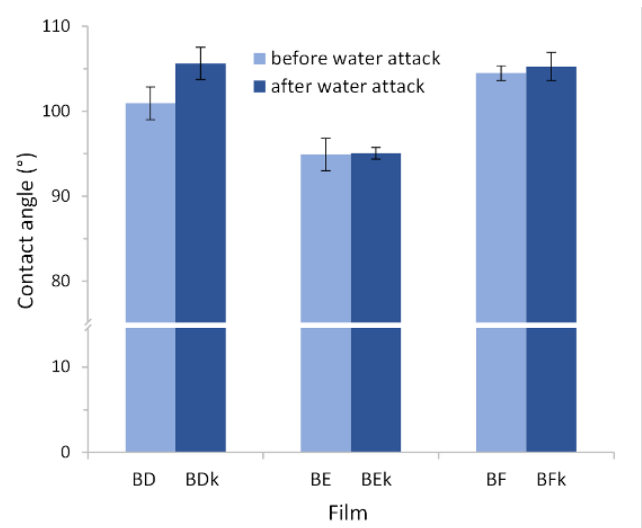

Figure 6. The influence of the way the sol was prepared at the boiling temperature of IPA as well as the water attack on the water contact angle of the inorganic-organic films.

The increase in the temperature of the sol preparation (from room temperature to the boiling temperature of IPA) caused a change in the effect the way of the sol preparation had on the contact angle of water. For films deposited from sols prepared at the boiling temperature of IPA (Figure 6), the way of mixing the initial precursors had the most marked effect on the contact angle for the films, which were prepared from the sol where TEOS and OTES were hydrolysed simultaneously, and this effect was observed for films before, as well as after, their water interaction. In comparison with other films, the $\mathrm{BE}$ and BEk films had the lowest water contact angle $\left(\sim 95^{\circ}\right)$. The lowest value of the contact angle shows that during the sol preparation, the reactions of OTES were not as "fast" and, therefore, the binding of its nonpolar $\equiv \mathrm{Si}\left(\mathrm{C}_{8} \mathrm{H}_{17}\right)$ groups was not as adequate in comparison with the other sols and the surface of the films prepared from the given sols had a lower hydrophobic characteristic. Considering the higher temperature of the sol preparation, the water attack caused only a slight increase in the contact angle of the film, which was deposited from the sol where OTES was added to the pre-hydrolysed TEOS (from $\sim 101^{\circ}$ for the $\mathrm{BD}$ film to $\sim 106^{\circ}$ for the $\mathrm{BDk}$ film).

\section{CONCLUSIONS}

In presented paper, the effect of a water attack at $80{ }^{\circ} \mathrm{C}$ on the properties of inorganic-organic films deposited from sols prepared at different conditions was studied. The sols in the "TEOS-OTES- $\mathrm{H}_{2} \mathrm{O}-\mathrm{HNO}_{3}-$ IPA" system were prepared in three different ways of mixing the initial precursors at two temperatures. The surface properties of the films were evaluated on the basis of the morphology, rms-roughness and water contact angle (hydrophobicity).

The surface morphology of the prepared inorganicorganic films markedly depends on the way the sol is prepared, mainly on the mixing the initial precursors, and consequently, it also has a subsequent effect on the surface morphology of the films after their water interaction.

The changes in the rms-roughness of films after the water attack are mainly affected by the way the initial precursors are mixed during the sol preparation as well as by the water interaction with the films. Before the water attack, the highest rms-roughness was observed for the films deposited from the sols which were prepared by mixing the separately pre-hydrolysed TEOS and OTES. However, after the water attack, the highest rms-roughness was observed for the films deposited from the sols which were prepared by adding OTES to the mixture, where only TEOS was pre-hydrolysed.

The films before and after the water attack are hydrophobic. The way the initial precursors are mixed had an effect on the water contact angle mainly for the films deposited from sols prepared at the boiling temperature of IPA and the water interaction with the films did not change the hydrophobicity.

Related to evaluating the interaction of the prepared inorganic-organic films with water, the lowest effect 
of the water attack on the films' properties was observed for the films deposited from the sol which was prepared by mixing TEOS and OTES at the beginning of the sol preparation, which means that both precursors were hydrolysed simultaneously. After the water attack, only small changes in the surface morphology as well as a slight increase in the rms-roughness and hydrophobicity were observed, mainly for films deposited from the sol prepared at room temperature. The largest change in the surface morphology after the water attack was observed for films deposited from the sol which was prepared by mixing the separately pre-hydrolysed TEOS and OTES and from the sol which was prepared by adding of OTES to the mixture with the pre-hydrolysed TEOS. For the film deposited from the sol which was prepared by the adding OTES to the pre-hydrolysed TEOS, the change in the surface morphology was also accompanied by a significant increase in the rms-roughness and a slight increase in the hydrophobicity.

In spite of the changes of the studied surface properties, it can be stated that the prepared inorganicorganic films are sufficiently resistant to the water attack and the observed changes in the hydrophobicity are mainly caused by the way the sol was prepared. Therefore, the given inorganic-organic films could be used as hydrophobic protective coatings.

\section{Acknowledgment}

This work was supported by the project VEGA 1/0431/18 of the Grant Agency of the Slovak Republic.

\section{REFERENCES}

1. Oyola-Reynoso S., Wang Z., Chen J., Çınar S., Chang B., Thuo M. (2015): Revisiting the challenges in fabricating uniform coatings with polyfunctional molecules on high surface energy materials. Coatings, 5, 1002-1018. doi:10.3390/coatings5041002

2. Brinker C.J., Scherer G.W. (1989). Sol-gel science: the physics and chemistry of sol-gel processing. Academic Press.

3. Carbajal-de la Torre G., Espinosa-Medina M.A., MartinezVillafañeA., Gonzalez-RodriguezJ.G., Castaño V.M.(2009): Study of ceramic and hybrid coatings produced by the solgel method for corrosion protection. The Open Corrosion Journal, 2, 197-203. doi: 10.2174/1876503300902010197

4. Zheng S., Li J. (2010): Inorganic-organic sol gel hybrid coatings for corrosion protection of metals. Journal of SolGel Science and Technology, 54, 174-187. doi:10.1007/ s10971-010-2173-1

5. Samadianfard R., Seifzadeh D., Habibi-Yangjeh A. (2021): Sol-gel coating filled with SDS-stabilized fullerene nanoparticles for active corrosion protection of the magnesium alloy. Surface and Coatings Technology, 419, 127292. doi:10.1016/j.surfcoat.2021.12729

6. Cao L., Hao H., Dutta P.K. (2018): Fabrication of highperformance antifogging and antireflective coatings using faujasitic nanozeolites. Microporous and Mesoporous Materials, 263, 62-70. doi:10.1016/j.micromeso.2017.12.0

7. Gómez M.J., Carvajal J.J., Bilousov, O., Díaz F., Aguiló M.
(2019): Investigation of antireflective and hydrophobic properties in polycrystalline GaN films with dual porosity produced by CVD. Scientific Reports, 9, 11686. doi:10.1038/s41598-019-48202-4

8. Exnar P. (2006). Metoda sol - gel. Technická univerzita v Liberci.

9. Gryčová A., Kejmarová G., Matoušek J. (2002): Corrosion of $\mathrm{SiO}_{2}$ and $\mathrm{TiO}_{2}$ sol-gel layers in water and diluted $\mathrm{HCl}$. Ceramics-Silikáty, 46, 49-51.

10. Novotný M., Matoušek J. (2008): Preparation of silver doped silica sol-gel layers. Ceramics-Silikáty, 52, 72-76.

11. VigneshR.B., Sethuraman M.G.(2014):Corrosion protection behaviour of sol-gel derived N,N-dimethylthiourea doped 3-glycidoxypropyltrimethoxysilane on aluminium. Progress in Organic Coatings, 77, 136-141. doi:10.1016/j. porgcoat.2013.08.01

12. Rao A.V., Latthe S.S., Mahadik S.A., Kappenstein, C. (2011): Mechanically stable and corrosion resistant superhydrophobic sol-gel coatings on copper substrate. Applied Surface Science, 257, 5772-5776. doi:10.1016/j. apsusc.2011.01.099

13. Kozuka H., Michihata T., Uchiyama H. (2011): Effects of fundamental processing parameters on the durability of sol-gel-derived silica thin films in water. Journal of the Ceramic Society of Japan, 119, 434-439. doi:10.2109/ jcersj2.119.434

14. Brusciotti F., Snihirova D.V., Xue H., Montemor M.F., Lamaka S.V., Ferreira, M.G.S. (2013): Hybrid epoxysilane coatings for improved corrosion protection of $\mathrm{Mg}$ alloy. Corrosion Science, 67, 82-90. doi:10.1016/j. corsci.2012.10.013

15. De Bardi M., Hutter H., Schreiner M., Bertoncello R. (2014): Sol-gel silica coating for potash-lime-silica stained glass: Applicability and protective effect. Journal of Non-Crystalline Solids, 390, 45-50. doi:10.1016/j. jnoncrysol.2014.02.016

16. Nocuń M., Środa M., Ciecińska M. (2015): Chemical resistance of $\mathrm{SiO} 2$ layers obtained by the sol-gel technique on a glass substrate. Optica Applicata, 45, 125-134. doi:10.5277/oa150112

17. Dal Bianco B., Bertoncello R. (2008).: Sol-gel silica coatings for the protection of cultural heritage glass. Nuclear Instruments and Methods in Physics Research Section B, 266, 2358-2362. doi:10.1016/j.nimb.2008.03.014

18. Carmona N., Villegas M.A., Navarro J.M.F. (2004): Protective silica thin coatings for historical glasses. Thin Solid Films, 458, 121-128. doi:10.1016/j.tsf.2003.12.064

19. Sanchez C., Julián B., Belleville P., Popall M. (2005): Applications of hybrid organic-inorganic nanocomposites. Journal of Materials Chemistry, 15, 3559-3592. doi:10.1039/b509097k

20. Kickelbick G. (2007). Introduction in hybrid materials, in: Kickelbick G. (Ed.): Hybrid Materials: Synthesis, Characterization and Applications. Wiley. pp. 1-48.

21. Schubert U. (2015). Sol-Gel Chemistry and Methods, in: Levy D., Zayat M. (Ed.): The Sol-Gel Handbook, Synthesis and Processing. Wiley. pp. 1-29.

22. Wojtach K., Laczka M., Cholewa-Kowalska K., Olejniczak Z., Sokolowska, J. (2007): Characteristics of colored inorganic-organic hybrid materials. Journal of Non-Crystalline Solids, 353, 2099-2103. doi:10.1016/j. jnoncrysol.2007.02.032 
23. Chou T., Chandrasekaran C., Cao G. (2003): Solgel-derived hybrid coatings for corrosion protection. Journal of Sol-Gel Science and Technology, 26, 321-327. doi:10.1023/A:1020736107842

24. Lamaka S.V., Montemor M.F., Galio A.F., Zheludkevich M.L., Trindade C., Dick L.F., Ferreira, M.G.S. (2008): Novel hybrid sol-gel coatings for corrosion protection of AZ31B magnesium alloy. Electrochimica Acta, 53, 47734783.doi:10.1016/j.electacta.2008.02.015

25. Figueira R.B., Silva C.J.R., Pereira E.V. (2014): Organicinorganic hybrid sol-gel coatings for metal corrosion protection: a review of recent progress. Journal of Coatings Technology and Research, 12, 1-35. doi:10.1007/s11998014-9595-6

26. Kesmez Ö. (2019): Hydrophobic, organic-inorganic hybrid sol-gel coatings containing boehmite nanoparticles for metal corrosion protection. Chemical Papers, 74, 673-688. doi:10.1007/s11696-019-00931-6

27. Chang Y.C., Lee C.C., Huang S.R., Kuo C.C., Wei, H.S. (2016): An easy and effective method to prepare superhydrophobic inorganic/organic thin film and improve mechanical property. Thin Solid Films, 618, 219-223. doi:10.1016/j.tsf.2016.02.034

28. Čierniková M., Balážová P., Plško A., Exnar P., Pagáčová J., Papučová I. (2018): Relation between chemical composition of sols and surface free energy of inorganicorganic films. Journal of Sol-Gel Science and Technology, 88, 497-507. doi:10.1007/s10971-018-4856-y

29. Parale V.G., Mahadik D.B., Mahadik S.A., Kavale M.S., Wagh P.B., Gupta S.C., Rao A.V. (2013): OTES modified transparent dip coated silica coatings. Ceramics International, 39, 835-840. doi:10.1016/j. ceramint.2012.05.079
30. Pantulap U., Petchareanmongkol B., Kaewdang W., Tapasa K. (2019): Optical transparent and hydrophobic properties of TEOS/OTES hybrid materials by sol-gel processing. Key Engineering Materials, 798, 134-139. doi:10.4028/www. scientific.net/kem.798.134

31. Zajícová V., Exnar P., Staňová I. (2011): Properties of hybrid coatings based on 3-trimethoxysilpropyl methacrylate. Ceramics-Silikáty, 55, 221-227.

32. Amiri S., Rahimi, A. (2016): Hybrid nanocomposite coating by sol-gel method: a review. Iranian Polymer Journal, 25, 559-577. doi:10.1007/s13726-016-0440-x

33. Holubová B., Cílová Zlámalová Z., Kučerová I., Zlámal M. (2015): Weatherability of hybrid organic-inorganic silica protective coatings on glass. Progress in Organic Coatings, 88, 172-180. doi:10.1016/j.porgcoat.2015.07.001

34. De Ferri L., Lottici P.P., Lorenzi A., Montenero A., Vezzalini, G. (2013): Hybrid sol-gel based coatings for the protection of historical window glass. Journal of Sol-Gel Science and Technology, 66, 253-263. doi:10.1007/s10971013-3002-0

35. Papučová I., Pagáčová J., Plško A. (2020): The influence of corrosion of inorganic-organic films on their surface properties. IOP Conference Series: Materials Science and Engineering, 776, 012103. doi:10.1088/1757899x/776/1/012103

36. Schuster J.M., Schvezov C.E., Rosenberger M.R. (2015): Influence of experimental variables on the measure of contact angle in metals using the sessile drop method. Procedia Materials Science, 8, 742-751. doi:10.1016/j. mspro.2015.04.131 